\section{SOI: $1.1 /$ TAS DOI: $10.15863 / \mathrm{TAS}$ International Scientific Journal Theoretical \& Applied Science}

p-ISSN: 2308-4944 (print) e-ISSN: 2409-0085 (online)

Year: 2018 Issue: 09 Volume: 65

Published: $24.09 .2018 \quad$ http://T-Science.org
Shehryar Noor

Dr., consultant general surgeon in Khyber Teaching

Hospital Peshawar, Pakistan. shehryar.md@gmail.com

Muhammad Ayub

Dr., Assistant Professor Gastroenterology in DHQ Teaching Hospital Gujranwala Medical College Gujranwala, Pakistan mnaich@hotmail.com

Nimra Iftikhar

Dr., WMO at govt Rural Dispensary Tarkhanawala,

Pakistan

nimraiftikhar200@gmail.com

\title{
PREVALENCE OF DIFFERENT TYPES OF COLORECTAL CARCINOMAS IN PATIENTS BELOW 40 YEARS AGE
}

\begin{abstract}
Objective: This study was conducted to determine prevalence of various histological forms of colorectal cancers among the patients having age less than 40 years.

Design and Setting: This is a cross sectional study of descriptive type. Study was conducted in Khyber Teaching Hospital Peshawar, Pakistan.

Duration of study: Study was started in January 2018 and completed in July 2018 having total duration of 7 months.

Patients and Methods: All patients presented in outdoor of the hospital under study during study period with signs and symptoms suggesting colorectal cancer were included in this study. Proper history taken and thorough clinical examination was done. Initially digital rectal examination was performed followed by proctoscopy, sigmoidoscopy, colonoscopy, ultrasound abdomen, CT scan abdomen with contrast. In which patient's tumor was suspected biopsy was taken and sent for histopathology. All important points of history and positive findings on clinical examination and investigations were documented properly. An inclusion and exclusion criterion was established according to which only those cases were included having age below 40 years, newly diagnosed cases, having no associated chronic disease and not operated previously for colorectal cancer. After establishing diagnosis staging workup was done. Some of the patients were referred to other institutions after establishing diagnosis and taking all necessary data for study. Treatment option was selected depending on the extent of tumor size and metastasis. TNM and Dukes systems were used for staging tumor. Data was analyzed on Microsoft office version 2012 and statistical softwares. Results presented in the form of table and figures.

Results: Total 136 cases were diagnosed with colorectal cancer and out of them 60 cases were below 40 years and above 15 years of age with mean age +-SD of 28+-11.5 years. Various diagnostic techniques were used in these cases such as proctoscopy in 35\% cases, digital rectal examination in 28.3\%, sigmoidoscopy in $34 \%$, colonoscopy in 25\%, barium enema done in 25\%, USG abdomen in 31.7\%, CT scan abdomen in $8.3 \%$ and exploratory laparotomy was performed in 3.3\% cases. There were $61 \%$ male and $39 \%$ were female cases. Different tumor positions were seen in study subjects in $50 \%$ cases rectum was involved, in $11.7 \%$ rectosigmoid junction, $1.7 \%$ descending colon and 3\% splenic flexure was involved. There were $68 \%$ cases with tumor in left colon. In $32 \%$ cases right side tumor present including $16.7 \%$ in caecum, $3.3 \%$ transverse colon, $8.3 \%$ hepatic flxure and $3.3 \%$ ascending colon.bIn $85 \%$ cases adenocarcinoma was diagnosed on histopathology. In 3.3\% carcinoid tumor, in $8.3 \%$ lymphoma and juvenile polyposis coli was present in $3.3 \%$ cases.

Conclusion: Colorectal carcinoma mostly involves left side colon with most common histological type of adenocarcinoma non-mucinous type. It has significance incidence in young age people below 40 years.

Key words: Colorectal cancer, adenocarcinom colon, prevalence of colonic cancer

Language: English

Citation: Noor S, Ayub M, Iftikhar N (2018) PREVALENCE OF DIFFERENT TYPES OF COLORECTAL CARCINOMAS IN PATIENTS BELOW 40 YEARS AGE. ISJ Theoretical \& Applied Science, 09 (65): 118-123.

Soi: http://s-o-i.org/1.1/TAS-09-65-18 Doi: crossef https://dx.doi.org/10.15863/TAS.2018.09.65.18
\end{abstract}

\section{INTRODUCTION}

Colorectal cancer is a most common malignancy of gastrointestinal tract. Early detection of disease and appropriate management by surgery or chemotherapy is effective and life saving and reduces mortality rate. It has many risk factors such as 
advance age and dietary factors like high fat, low fiber diet as high fiber diet is protective against this disease. ${ }^{1}$ Smoking and alcohol consumption, ureterosigmoidostomy, pelvic radiation therapy, inflammatory bowel disease as ulcerative colitis, crohn disease and familial adenomatous polyposis, hereditary non polyposis colon cancer and adenomas greater than $1 \mathrm{~cm}$ size are risk factors of colorectal cancer. ${ }^{2}$ Positive familial history of any malignancy is a strong risk factor in such cases screening should be done by serum CEA level. CEA level is used for screening of colorectal carcinoma and especially it is indicator of its recurrence. ${ }^{3}$ This tumor may spread locally in longitudinal or transverse direction causing intestinal obstruction and lymphatic spread may involve pericolic, peri rectal and mesenteric lymphnodes. ${ }^{4}$ Spread through blood occurs to liver, lungs and brain. This cancer is more common in male population as compared to females. This malignancy is much prevalent in developed countries as well such as in America incidence is $6 \%$ every year. Most of the patients develop this malignancy without any risk factors and just $25-30 \%$ patients with this cancer have risk factors associated with it. ${ }^{5}$ There are many systems for staging of this malignancy such as Dukes staging, TNM staging. Patients with colorectal cancer present usually with per rectal bleeding, anemia and palpable abdominal mass. If tumor involves right colon then presentation will be right abdominal mass, anemia is more common in right side tumor, intestinal obstruction and appendicitis may occur due to blockage of lumen of appendix. ${ }^{6}$ Such patients may present in emergency ward due to intestinal obstruction or perforation requiring laparotomy. Tumor of left colon presents with lower abdominal pain, obstruction, tenesmus, colovesical fistula. Rectal tumor may present with bleeding, something coming out of anus, sense of incomplete evacuation of rectum diarrhea and constipation and weight loss. In metastatic disease altered consciousness, hemoptysis and portal hypertension or ascites may be present. Poor prognostic factor include young age, distal tumor location and undifferentiated on histopathology with advance stage or metastasis. ${ }^{7-9}$ In advance metastatic tumor just palliative surgery for debulking or palliative chemotherapy is required. According to a report each year one million people in the world suffer from this cancer and about half of them die within five year. In previous few years incidence of colorectal cancer has been increased significantly in asian countries including Pakistan. Surgical management includes anterior resection, abdominoperineal resection and Hartman's operation. Chemotherapy is given in stage 3 tumors as it has no role in initial stage of tumors. Drugs of chemotherapy include 5-fluorouracil, folinic acid and oxaliplatin etc. Radiotherapy has no role in this malignancy.

\section{Patients and Methods}

This is a cross sectional study of descriptive type conducted in ateaching hospital of Pishawar pakisttan. In this study patients from OPD were selected falling on our inclusion criteria.All patients presented in surgical outdoor during study period with signs and symptoms suggesting colorectal cancer were included in this study. Colorectal cancer is a most common malignancy of gastrointestinal tract. Early detection of disease and appropriate management by surgery or chemotherapy is effective and life saving and reduces mortality rate. It has many risk factors such as advance age and dietary factors like high fat, low fiber diet as high fiber diet is protective against this disease. Proper history taken and thorough clinical examination was done. Initially digital rectal examination was performed followed by proctoscopy, sigmoidoscopy, colonoscopy, ultrasound abdomen, CT scan abdomen with contrast. In which patient tumor was suspected biopsy was taken and sent for histopathology. All important points of history and positive findings on clinical examination and investigations were documented properly. An inclusion and exclusion criterion was established according to which only those cases were included having age below 40 years, newly diagnosed cases, having no associated chronic disease and not operated previously for colorectal cancer. After establishing diagnosis staging workup was done. Treatment option was selected depending on the extent of tumor size and metastasis. TNM and Dukes systems were used for staging tumor. Data was analyzed on Microsoft office version 2012 and statistical software. Results presented in the form of table and figures. In study cases baseline investigations were done such as CBC, RFTs, LFTs, PT, INR and for metastatic workup $\mathrm{Ct}$ abdomen, $\mathrm{CT}$ brain and chest $\mathrm{X}$-ray were done. ECG was also done in patients who were planned for laparotomy. In our study no patient died due to colorectal cancer during study period of seven months and mortality may occur afterward due to advance disease. During laparotomy tumor was identified, located and if resectable then removed and diversion colostomy or ileostomy was made. These cases were kept in the syrgical unit of study institution for monitoring.

\section{Results}

This study was done in Khyber teaching hospital Peshawar where daily 150-200 cases report in surgical outpatient door. Tota136 cases were diagnosed with colorectal cancer and out of them $60(46.2 \%)$ cases were below 40 years and above 15 years of age with mean age +-SD of 28+-11.5 years. Various diagnostic techniques were used in these 


\begin{tabular}{l|lr|ll|ll} 
& ISRA (India) & $=\mathbf{1 . 3 4 4}$ & SIS (USA) & $=\mathbf{0 . 9 1 2}$ & ICV (Poland) & $=\mathbf{6 . 6 3 0}$ \\
Impact Factor: & ISI (Dubai, UAE) $=\mathbf{0 . 8 2 9}$ & PUHЦ (Russia) $=\mathbf{0 . 1 5 6}$ & PIF (India) & $=\mathbf{1 . 9 4 0}$ \\
& GIF (Australia) & $\mathbf{0 . 5 6 4}$ & ESJI (KZ) & $=4.102$ & IBI (India) & $=\mathbf{4 . 2 6 0}$ \\
& JIF & $=\mathbf{1 . 5 0 0}$ & SJIF (Morocco) & $=2.031$ & & \\
\hline
\end{tabular}

cases such as proctoscopy in $21(35 \%)$ cases, digital rectal examination in17 (28.3\%), sigmoidoscopy in 14(34\%), colonoscopy in 12(25\%), barium enema done in $15(25 \%)$, USG abdomen in 19(31.7\%), CT scan abdomen in 5(8.3\%) and exploratory laparotomy was performed in $3.3 \%$ cases. There were $37(61.7 \%)$ male and $23(38.3 \%$ ) were female cases. Different tumor positions were seen in study subjects in $30(50 \%)$ cases rectum was involved, in $7(11.7 \%)$ rectosigmoid junction, $1(1.7 \%)$ descending colon and $3(5 \%)$ splenic flexure was involved. There were $41(68 \%)$ cases with tumor in left colon. In $19(32 \%)$ cases right side tumor present including $10(16.7 \%)$ in caecum, $2(3.3 \%)$ transverse colon, $5(8.3 \%)$ hepatic flexure and $2(3.3 \%)$ ascending colon. In 51(85\%) cases adenocarcinoma was diagnosed on histopathology. In 2(3.3\%) carcinoid tumor, in $5(8.3 \%)$ lymphoma and juvenile polyposis coli was present in $2(3.3 \%)$ cases.

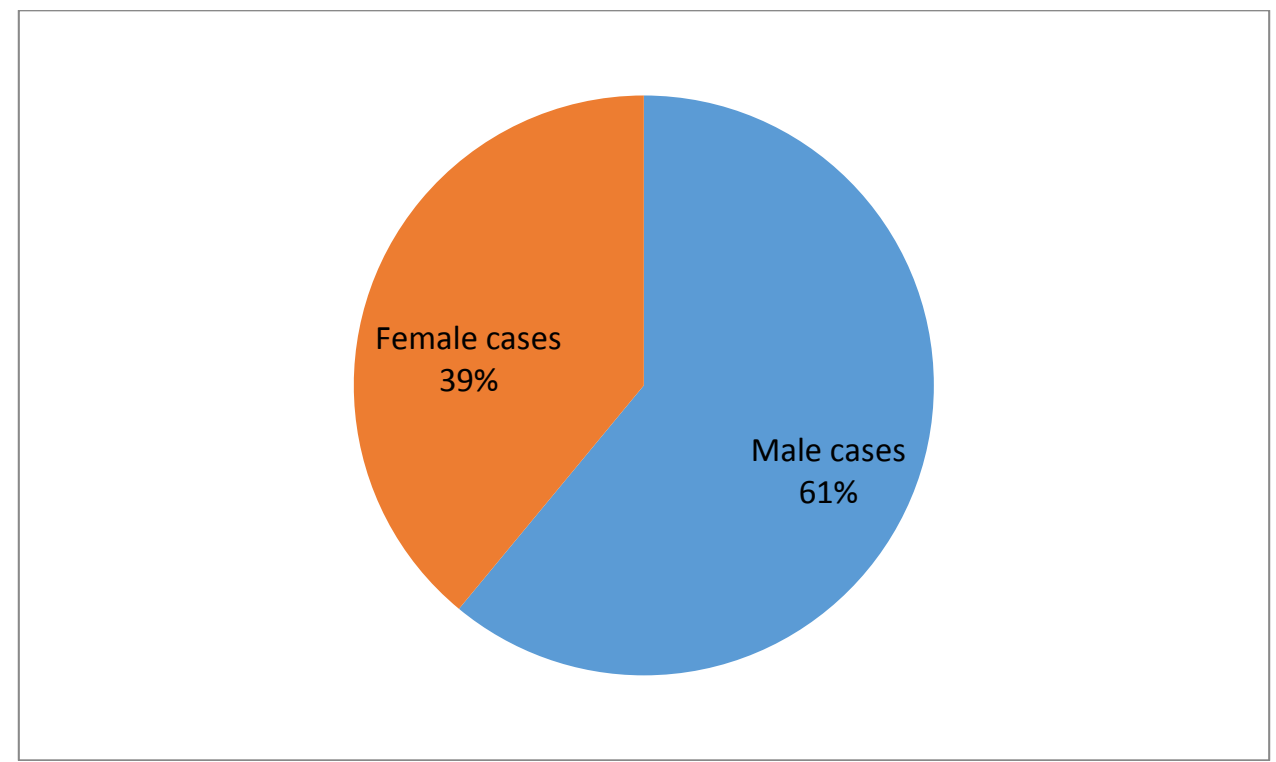

Figure-1 Frequency of male and female patients in study group

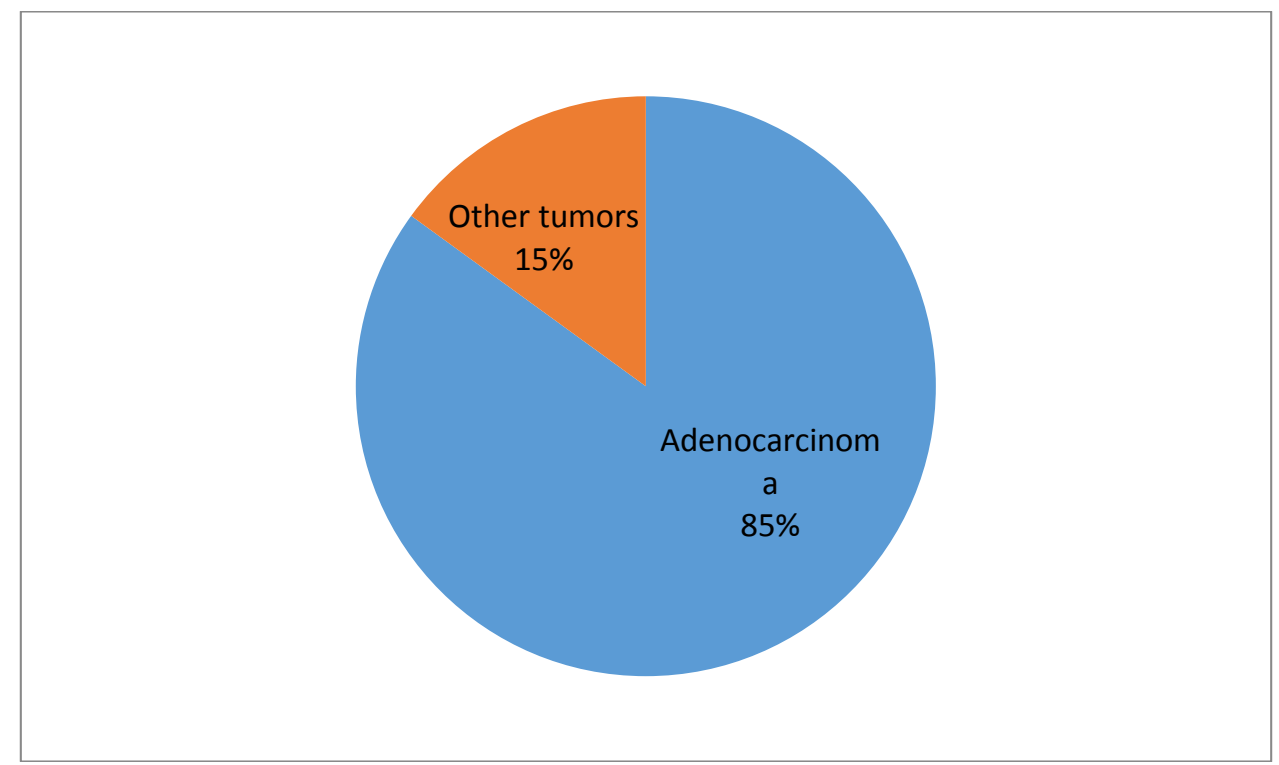

Figure-2 Frequency of adenocarcinoma compared to other tumor types in study group 


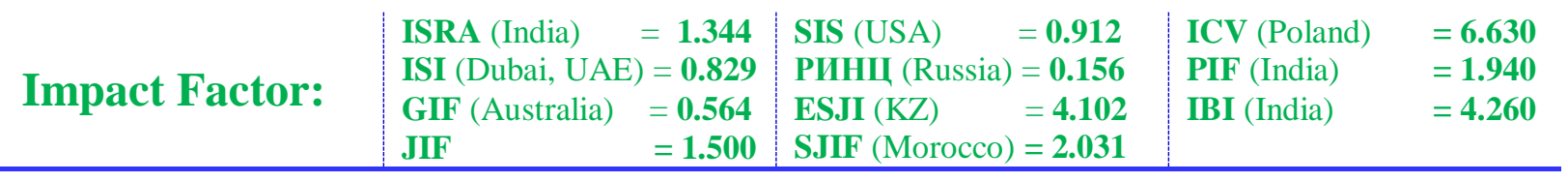

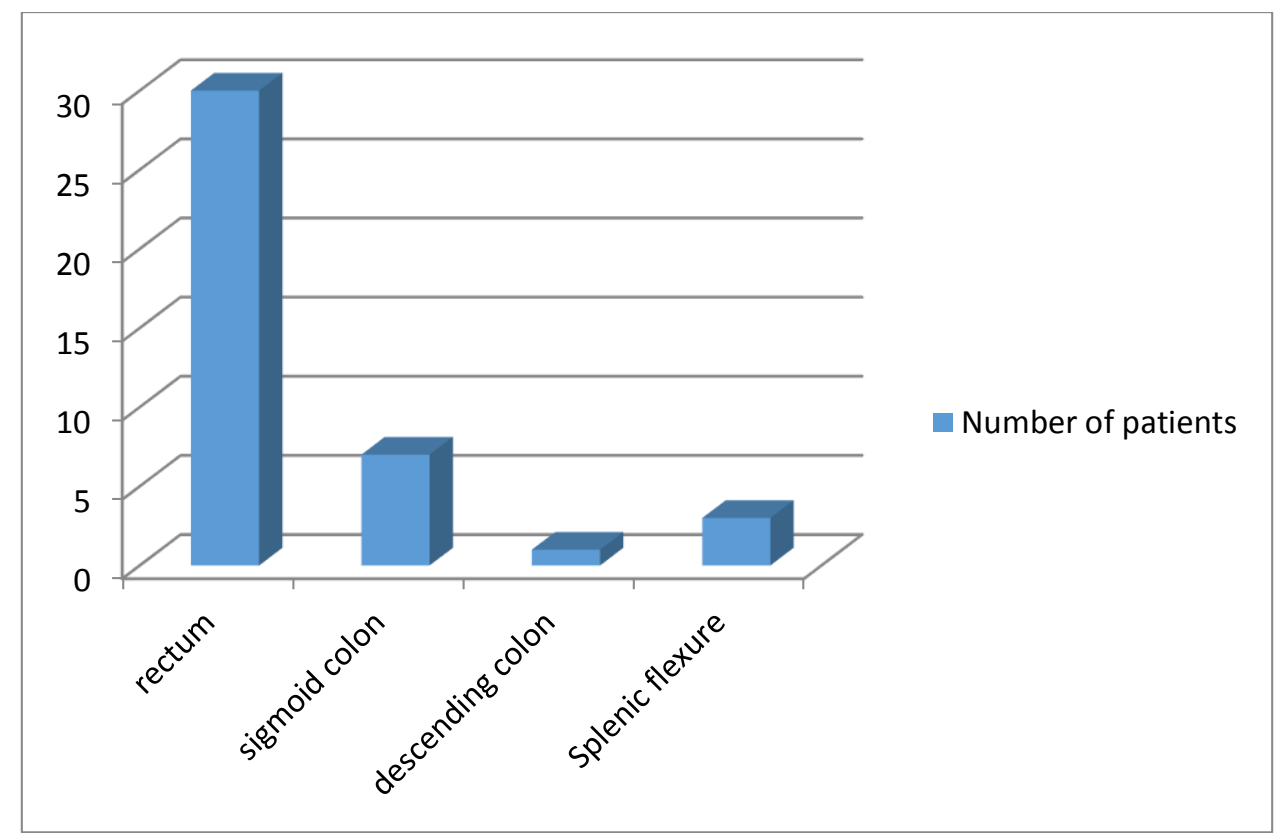

Figure-3 Different Locations of tumor in left colon

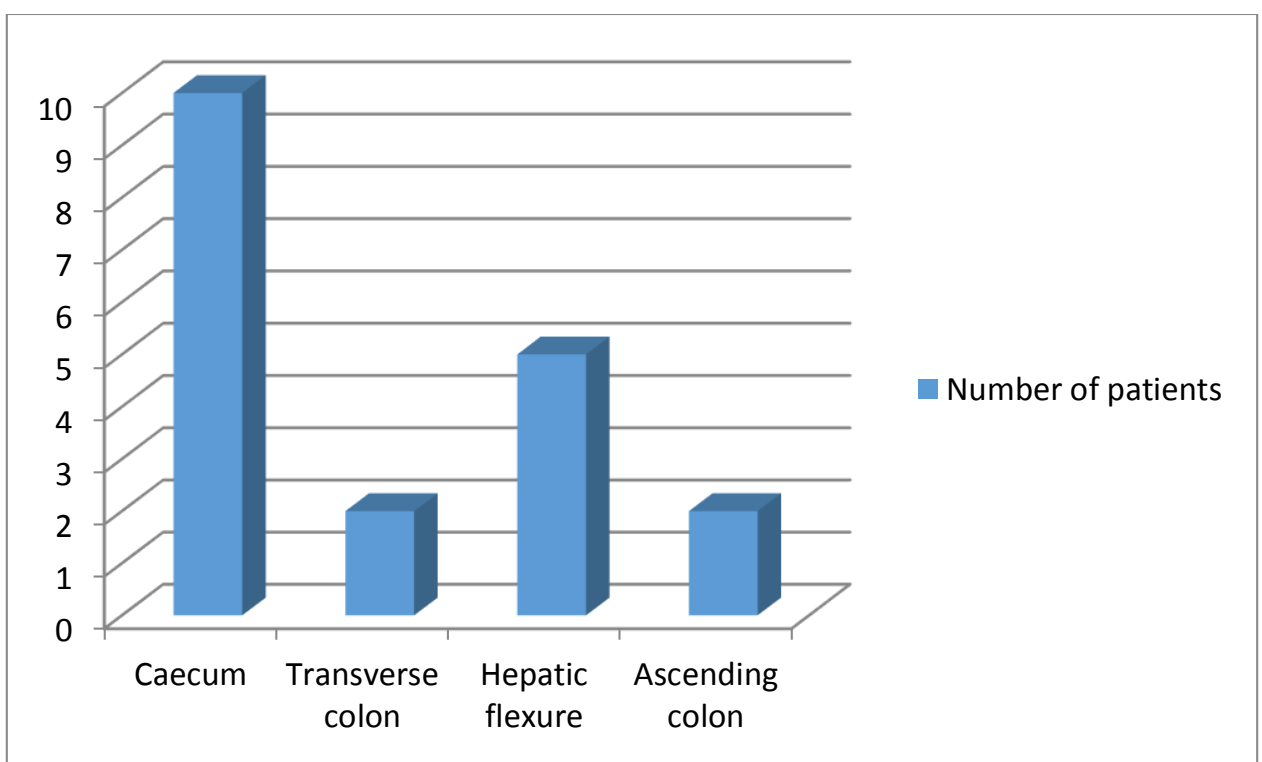

Figure-4 Different Locations of tumor in right colon

Table-1

Histological types of colorectal carcinoma and their frequency

\begin{tabular}{|c|c|c|}
\hline \multicolumn{1}{|c|}{ Histopathology Type } & Number of patients & \% \\
\hline Adenocarcinoma type & & 46.7 \\
\hline a) Well differentiated & 28 & 15 \\
\hline b) Poorly differentiated & 9 & 23.3 \\
\hline c) Undifferentiated & 14 & 8.3 \\
\hline Lymphoma & 5 & 3.3 \\
\hline Juvenile polyposis coli & 2 & 3.3 \\
\hline Carcinoid & 2 & $\mathbf{1 0 0}$ \\
\hline Total & $\mathbf{6 0}$ & \\
\hline
\end{tabular}


Age distribution among the patients in study group

\begin{tabular}{|c|c|c|}
\hline Age of patients & Number of cases & $\%$ \\
\hline $15-20$ & 6 & 10 \\
\hline $21-25$ & 14 & 23.3 \\
\hline $26-30$ & 20 & 33.3 \\
\hline $31-35$ & 16 & 26.7 \\
\hline $36-39$ & 4 & 6.6 \\
\hline
\end{tabular}

\section{DISCUSSION}

Colorectal cancer is the most common malignancy of gastrointestinal tract. Prevalence of this disease is different in various countries. ${ }^{10}$ It is not much common in Asian countries. In America its incidence was reported highest. European countries has higher incidence as compared to Asian countries. Colorectal cancer is a most common malignancy of gastrointestinal tract. ${ }^{11}$ Early detection of disease and appropriate management by surgery or chemotherapy is effective and life saving and reduces mortality rate. It has many risk factors such as advance age and dietary factors like high fat, low fiber diet as high fiber diet is protective against this disease. $^{12}$ Smoking and alcohol consumption, ureterosigmoidostomy, pelvic radiation therapy, inflammatory bowel disease as ulcerative colitis, crohn disease and familial adenomatous polyposis, hereditary non polyposis colon cancer and adenomas greater than $1 \mathrm{~cm}$ size are risk factors of colorectal cancer. Positive familial history of any malignancy is a strong risk factor in such cases screening should be done by serum CEA level. CEA level is used for screening of colorectal carcinoma and especially it is indicator of its recurrence. ${ }^{13}$ This is a cross sectional study of descriptive type conducted in ateaching hospital of Pishawar pakisttan. In this study patients from OPD were selected falling on our inclusion criteria.All patients presented in surgical outdoor during study period with signs and symptoms suggesting colorectal cancer were included in this study. Colorectal cancer is a most common malignancy of gastrointestinal tract. Early detection of disease and appropriate management by surgery or chemotherapy is effective and life saving and reduces mortality rate. ${ }^{14}$ This study was done in Khyber teaching hospital Peshawar where daily 150-200 cases report in surgical outpatient door. Tota136 cases were diagnosed with colorectal cancer and out of them $60(46.2 \%)$ cases were below 40 years and above 15 years of age with mean age +-SD of 28+11.5 years. There are many systems for staging of this malignancy such as Dukes staging, TNM staging. Patients with colorectal cancer present usually with per rectal bleeding, anemia and palpable abdominal mass. If tumor involves right colon then presentation will be right abdominal mass, anemia is more common in right side tumor, intestinal obstruction and appendicitis may occur due to blockage of lumen of appendix. ${ }^{15}$ Such patients may present in emergency ward due to intestinal obstruction or perforation requiring laparotomy. Tumor of left colon presents with lower abdominal pain, obstruction, tenesmus, colovesical fistula. Rectal tumor may present with bleeding, something coming out of anus, sense of incomplete evacuation of rectum diarrhea and constipation and weight loss. ${ }^{16-19}$ Different tumor positions were seen in study subjects in $30(50 \%)$ cases rectum was involved, in $7(11.7 \%)$ rectosigmoid junction, $1(1.7 \%)$ descending colon and $3(5 \%)$ splenic flexure was involved. There were $41(68 \%)$ cases with tumor in left colon. In $19(32 \%)$ cases right side tumor present including $10(16.7 \%)$ in caecum, $2(3.3 \%)$ transverse colon, $5(8.3 \%)$ hepatic flexure and $2(3.3 \%)$ ascending colon. According to a study done in Karachi city of Pakistan, incidence of adenocarcinoma was $71.7 \%$. Other study done in pakistan by Malik et al reported highest frequency of well differentiated adenocarcinoma in $35.7 \%$ cases followed by anaplastic tumors and mucinous adenocarcinoma with least frequency.

\section{CONCLUSION}

Colorectal carcinoma is most prevalent tumor of large intestine worldwide. This is more prevalent in European countries as compared to Asian countries. Adenocarcinoma is most common histopathological type of colorectal cancer. It has significant incidence in young age group people. Most common location $\mathrm{f}$ tumor is in left colon especially rectum. Right sided tumors are less common. Early detection of cancer and management by surgery and chemotherapy may decrease morbidity and mortality. 


\begin{tabular}{l|lr|ll|ll} 
& ISRA (India) & $=\mathbf{1 . 3 4 4}$ & SIS (USA) & $=\mathbf{0 . 9 1 2}$ & ICV (Poland) & $=\mathbf{6 . 6 3 0}$ \\
Impact Factor: & ISI (Dubai, UAE) $=\mathbf{0 . 8 2 9}$ & PUHL (Russia) $=\mathbf{0 . 1 5 6}$ & PIF (India) & $=\mathbf{1 . 9 4 0}$ \\
& GIF (Australia) & $\mathbf{0 . 5 6 4}$ & ESJI (KZ) & $=4.102$ & IBI (India) & $=\mathbf{4 . 2 6 0}$ \\
& JIF & $=\mathbf{1 . 5 0 0}$ & SJIF (Morocco) $=\mathbf{2 . 0 3 1}$ & & \\
\hline
\end{tabular}

\section{References:}

1. Malik KA. (2007) Colorectal carcinoma: a six years experience at a tertiary care hospital of Sindh. J Liaqat Uni Med Health Sci 2007; 74-6.

2. Steel RJC. (2004) Disorders of the colon and rectum. In: Cuschieri SA, Steel RJC, Mossa AR, eds. Essentials surgical practice. 4th ed. London: Arnold, 2004: 569-626.

3. Williams NS. (2004) The rectum. In: Russell RCG, Williams NS, Bulstrode CJ, eds. Bailey and Love's short practice of surgery. 24th ed. London: Arnold, 2004: 1219-41.

4. Ries LAG, Eisuer MP, Kosary CL. (2005) Cancer statistics review 1975-2000, Bethesda MD: National Cancer Institute, USA. 2005.

5. Giovannucci E, Wu K. (2006) Cancers of the colon and rectum. In: Schottenfeld D, Fraumeni J, eds. Cancer. Epidemiology and Prevention. 3rd ed. Oxford University Press; 2006.

6. Dorundi S, Banerjea A. (2006) Colorectal cancer: early diagnosis and predisposing causes. Surg Int (Pakistan edition) 2006; 73: 131-6.

7. Kettlewell MGW. (1994) Colorectal cancer and benign tumors of the colon. In: Morris PJ, Malt RA, eds. Oxford textbook of surgery. New York: Oxford University Press, 1994: 1060-88.

8. Crawford JM. (2004) The gastrointestinal tract: small and large intestine. In: Cotran RS, Kumar V, Collins T, eds. Robbins pathologic basis of disease. 7th ed. Philadelphia: WB Saunders, 2004: 602-43.

9. Sule AZ, Mandony BM. (1999) Malignant colorectal tumors in patients 30 years and below: a review of 35 cases. Cent Afr J Med 1999; 45:209-12.

10. O' Connell JB, Maggard MA, Livingston EH, Ko CY. (2004) Colorectal cancer in the young. Am J Surg 2004; 187: 343-8.

11. Alici S, Aykan NF, Sakar B, Bulutlar G, Kaytan E, Topuz E. (2003) Colorectal cancer in young patients: characteristics and outcome. Tohoku J Exp Med 2003; 199: 85-93

12. Soreide K, Janssen MAE, Soiland H, Korner H, Baak APJ. (2006) Microsatellite instability in colorectal cancer. Br J Surg 2006; 93: 395-406.

13. Sung JJ, Lau JY, Goh KL, Leung WK. (2005) Asia Pacific Working Group on Colorectal Cancer. Increasing incidence of colorectal cancer in Asia: implication for screening. Lancet Oncol 2005; 6: 871-6.

14. Lin JT, Wang WS, Yen CC, Liu JH, Yang MH, Chao TC, et al. (2005) Outcome of colorectal carcinoma in patients under 40 years of age. J Gastroenterol Hepatol 2005; 20: 900-5.

15. Karimi Zarchi AA, Saadat AR, Jalalian HR, Esmaeili M. (2011) Epidemiology and survival analysis of colorectal cancer and its related factors. Kowsar Med J 2011 Winter;15(4):23943.

16. Ahmed Z, Azad NS, Rauf F, Yaqoob N, Husain A, Ahsan A, et al. (2007) Frequency of primary solid malignant neoplasms in different age groups as seen in our practice. J Ayub Med Coll Abbottabad 2007;19(3):56-63.

17. Ahmad Z, Idrees R, Ahmed R, Kayani N, Pervez P, Hasan SH. (2005) Colorectal Carcinoma, extent and spread in our Population. Resection specimens give valuable information. J Pak Med Assoc 2005;55:483-5.

18. Al Jaberi TM, Yagha RJ, EL Heis HA. (2003) Colorectal cancer in young patients under 40 years of Age; comparison with old patients in a well defined Jordanian population. Saudi Med J 2003;24:871-4.

19. EL Henna WY, MM Mousa ME, el saeidy MK. (2003) Rectal carcinoma in Egyptian patients less than 40 years of age. Int Surg 2003;88:13744. 